REVIEW ARTICLE

\title{
Environmental, genetic and epigenetic contributions to cocaine addiction
}

\author{
R. Christopher Pierce ${ }^{1}$, Bruno Fant ${ }^{1}$, Sarah E. Swinford-Jackson ${ }^{1}$, Elizabeth A. Heller ${ }^{2}$, Wade H. Berrettini ${ }^{1}$ and Mathieu E. Wimmer ${ }^{3}$
}

Decades of research on cocaine has produced volumes of data that have answered many important questions about the nature of this highly addictive drug. Sadly, none of this information has translated into the development of effective therapies for the treatment of cocaine addiction. This review endeavors to assess the current state of cocaine research in an attempt to identify novel pathways for therapeutic development. For example, risk of cocaine addiction is highly heritable but genome-wide analyses comparing cocaine-dependent individuals to controls have not resulted in promising targets for drug development. Is this because the genetics of addiction is too complex or because the existing research methodologies are inadequate? Likewise, animal studies have revealed dozens of enduring changes in gene expression following prolonged exposure to cocaine, none of which have translated into therapeutics either because the resulting compounds were ineffective or produced intolerable side-effects. Recently, attention has focused on epigenetic modifications resulting from repeated cocaine intake, some of which appear to be heritable through changes in the germline. While epigenetic changes represent new vistas for therapeutic development, selective manipulation of epigenetic marks is currently challenging even in animals such that translational potential is a distant prospect. This review will reveal that despite the enormous progress made in understanding the molecular and physiological bases of cocaine addiction, there is much that remains a mystery. Continued advances in genetics and molecular biology hold potential for revealing multiple pathways toward the development of treatments for the continuing scourge of cocaine addiction.

Neuropsychopharmacology (2018) 43:1471-1480; https://doi.org/10.1038/s41386-018-0008-x

\section{INTRODUCTION}

The estimated percentage of US residents who are current users of cocaine has remained more or less constant since 2007, which unfortunately translates to a steady state of nearly 2 million Americans who use cocaine at least monthly, or around $0.7 \%$ of the population aged 12 or older. It is estimated that over 850,000 Americans meet the DSM-IV criteria for cocaine dependence [1]. The cocaine abuse epidemic continues to plague each generation of US citizens. Indeed, young adults have the highest percentage of current users and an estimated 29,000 US adolescents are cocaine dependent [1]. Clearly cocaine addiction is and remains a serious public health issue in the US and worldwide.

Despite decades of intense research effort, there remain no effective treatments for cocaine addiction. This is particularly frustrating since there are at least somewhat effective therapeutic options for opioid, alcohol, and nicotine addiction. A broad array of agents acting in the central nervous system (CNS), some with stronger rationales than others, have been assessed as potential cocaine addiction therapeutics [2, 3]. All have failed. Even substitution therapy, that is using an orally administered psychostimulant such as amphetamine or methylphenidate to minimize cocaine withdrawal and craving, has had mixed success [4-7]. Moreover, the doses of psychostimulants tested to treat cocaine dependence produce relatively high rates of adverse events including sleeping problems, agitation, irritability and increased heart rate [4].
It has long been appreciated that environmental and genetic factors influence the propensity to become addicted to drugs of abuse, including cocaine. More recently, changes in epigenetic modulation of gene expression have emerged as another factor contributing to the development of addiction. Some of these epigenetic modifications are heritable, leading to changes in descendent physiology and behavior. This review focuses on environmental, genetic and epigenetic factors (including transgenerational effects) that contribute to risk of cocaine addiction. The emphasis is on the identification of physiological targets based on this research that may serve as platforms for the development of cocaine addiction therapeutics.

\section{ENVIRONMENT}

An intuitive prediction would be that easy access to cocaine is more likely to lead to cocaine use escalating to addiction relative to an environment in which cocaine is not present. This commonsense assumption is supported by human twin studies indicating the importance of shared environmental experiences on addiction risk $[8,9]$, which is a factor for addiction to all classes of abused substances rather than being drug specific $[8,9]$. As an example, exposure to parental cocaine use increases the risk of substance abuse generally but not necessarily cocaine addiction specifically. Known environmental risk factors for addiction include drug

\footnotetext{
${ }^{1}$ Department of Psychiatry, Center for Neurobiology and Behavior, Perelman School of Medicine at the University of Pennsylvania, Philadelphia, PA 19104, USA; ${ }^{2}$ Department of

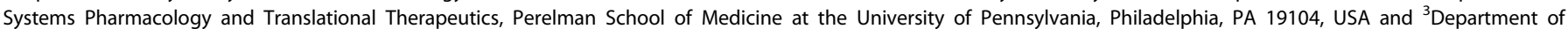
Psychology, Temple University, Philadelphia, PA 19122, USA

Correspondence: R Christophe Pierce (rcpierce@pennmedicine.upenn.edu)
}

Received: 29 September 2017 Revised: 21 December 2017 Accepted: 30 December 2017

Published online: 5 February 2018 
1472

availability, childhood abuse, parental attitude regarding drug use, household drug use, peer drug use and lack of participation in social activities; somewhat surprisingly parental supervision/ monitoring does not appear to be a risk factor for the initiation of cocaine use [10].

The two major twin studies of addictions $[8,9]$ reported broadly similar results with one major exception. The earlier study indicated that, unlike other illicit drugs of abuse, most of the genetic effects on heroin addiction were unique to this substance [8]. Interestingly, this article focused exclusively on twins who served in the military during the Vietnam war era [8]; those soldiers serving in southeast Asia were exposed to an environment in which heroin was readily available. Subjects in the subsequent study in which heroin-specific heritability was not observed, in contrast, were derived from the Virginia Twin Registry [9]. Rates of heroin exposure were lower in the Virginia sample and heroin-specific heritability was not observed [9]. Although this work did not focus on cocaine, it is an excellent example of the general influence of drug availability on drug use and dependence, which skewed the results of the report from Tsuang and colleagues.

Numerous animal studies also have documented the effect of environment on subsequent drug self-administration. These studies primarily focus on environmental enrichment, which consists of group housing in larger enclosures with running wheels, toys, and other features that rodents find appealing. Although this is the accepted nomenclature, there is general acknowledgement in the field that these "enriched" environments are actually closer to a natural environment, whereas the comparison standard environment could be characterized as impoverished [11]. Numerous studies have examined the effects of rodent enriched environment on stimulant-associated behaviors. An early study showed that environmental enrichment enhanced cocaine self-administration in rats using a two-bottle choice paradigm [12]. Consistent with this finding, environmental enrichment increased amphetamineinduced conditioned reward in rats [13]. However, the same group that published this amphetamine finding subsequently reported that environmental enrichment decreased i.v. amphetamine selfadministration in male and female rats $[14,15]$. It also has been shown that environmental enrichment makes rats less sensitive to the discriminative stimulus effects of cocaine and amphetamine [16] and, in mice, environmental enrichment decreased cocaine conditioned reward $[17,18]$. On balance, these results indicate that environmental enrichment blunts the reinforcing effects of stimulants. This conclusion fits well within the framework established by the clinical literature, whereby participation in social activities are highly predictive of reduced susceptibility to develop substance use disorder [19]. These findings were also the basis of the long-held idea that the etiology of addiction emanates from complex interactions between environmental and genetic factors.

\section{GENETICS}

Drug dependence is highly familial. Thus, rates of cocaine, opioids, alcohol, marijuana, and nicotine dependence are increased in siblings and relatives of drug dependent individuals [20,21]. Two major population based twin studies examined the major classes of addictive drugs, revealing that genetics is a substantial risk factor in every instance $[8,9]$. Moreover, as noted above, abuse of drugs in one class is highly correlated with drug dependence in other categories, suggesting a common vulnerability [8]. In terms of the stimulants, relatively little genetic variance is stimulant specific [8]. These results indicate that genetic factors predisposing individuals to drug abuse are common across classes of addictive substances $[9,22]$. Importantly, these conclusions apply to both males and females [23]. Interestingly, as a side note, the genetic risk factors for abuse of illicit drugs appear to differ from alcohol and nicotine [23]. The finding that the genetics of addiction are similar across illicit substances indicates that genetic variation in the primary site of action of various drugs of abuse is not likely to contribute substantially to increased risk of substance use disorder [22].

Drug addiction is among the most heritable of psychiatric disorders, with the heritability of cocaine estimated at $65 \%$ for females [24] and 79\% in males [25]. Although other cocaine heritability estimates are somewhat lower than these values [23, 26], genetic influences consistently explain the majority of risk for cocaine addiction [27]. There is not a clear pattern of Mendelian transmission, suggesting that addiction heritability is likely polygenic [28]. The monozygotic:dizygotic twin concordance ratios for the inheritance of addiction are low for all drugs of abuse with the exception of cocaine. A ratio of $4: 1$ for cocaine suggests that multiple alleles functioning in combination may underlie the heritability of cocaine addiction [27]. Candidate genedriven approaches have revealed a number of single nucleotide polymorphisms (SNPs) associated with aspects of cocaine addiction [29] in proximity to genes including dopamine beta hydroxylase [30], neuron-specific vesicular protein (as known as calcyon) [31], catechol-O-methyltransferase [32, 33], neuronal calcium sensor 1 [34], L-type calcium channel CACNA1D [35], cannabinoid receptor $1[36,37]$, delta opioid receptor [38, 39] tryptophan hydroxylase-2 [40], and Homer 1 [41]. Although these findings are compelling, several of these results have not yet been replicated and it is not clear that any of these genes, with the possible exception of delta opioid receptors and L-type calcium channels, represent clearly viable targets for novel drug development.

As noted above, the available evidence indicates that common genetic factors underlie the addiction liability of all illicit drugs of abuse $[8,9,22]$. The missense polymorphism rs16969968:G $>A$ in CHRNA5, which encodes an amino acid change (D398N) that leads to hypofunctionality of $(\alpha 4 \beta 2)_{2} a 5$ nicotinic acetylcholine receptors (nAChRs) [42], is associated with risk for nicotine addiction [43-46]. This association is likely the most replicated finding in the human psychiatric genetics literature [47]. It was reasonable, therefore, to posit that rs16969968:G > A might also play a role in cocaine addiction. This hypothesis was tested through a genetic association analysis, which revealed a significant association between the CHRNA5 variant rs16969968 and cocaine addiction, but the direction was opposite that of nicotine addiction [48]. That is, expression of the A relative to the $G$ allele of $r s 16969968$ in CHRNA5 is a risk factor for nicotine addiction but is protective for cocaine addiction [48-50]. The physiological basis of this distinction is not completely clear but animal studies show that $\mathrm{nAChR}$ antagonists decrease the reinforcing effect of cocaine [51, 52], whereas mice with a null mutation of Chrna5 increase their intake of higher doses of nicotine [53].

To date, only one genome wide association study (GWAS) specifically focused on cocaine dependence has been published [54]. Using a symptom count-based analytic approach, one genome-wide significant association with cocaine dependence at rs2629540 was identified. This SNP maps to an intron of the FAM53B (family with sequence similarity 53 , member B) gene on chromosome 10 [55]. FAM53B has not been studied extensively, such that its function is not clear. A gene homolog in fish is associated with cell proliferation [56] and axonal extension during development [57]. Changes in several other SNPs were identified with near genome-wide significance, which were associated with genes encoding voltage-gated sodium and potassium channels as well as cyclin-dependent kinase 1 [55]. A systems genetics study that assessed cocaine self-administration in 39 strains of recombinant inbred BDX mice revealed that Fam53b was one of six genes that exhibited midbrain expression levels that mapped to the cocaine self-administration behavioral quantitative trait loci [58].

It has been difficult to identify common germline alleles that explain even a small amount of the risk (e.g., odds ratios $>1.3$ ) for cocaine addiction [55]. Part of the reason for this is the fact that 
human GWASs require subject pools numbering in the tens of thousands to achieve appropriate statistical power [59]. This is a situation where animal studies represent an alternative, costeffective means to identify alleles associated with relative levels of cocaine use. Unfortunately, few insights have emerged from the preclinical literature, which may be partially due to the fact that self-administration experiments in mice, the non-human species of choice for genetic studies, are methodologically difficult. However, a few studies in mice have addressed this issue. For example, B x D mice strains with poor reversal learning (a measure of inhibitory control over impulsive responding) acquired cocaine self-administration more readily and maintained higher rates of cocaine intake relative to strains with good reversal learning [60]. These results suggest that heritable differences in inhibitory control affect cocaine self-administration [60]. Consistent with these findings in rodents, fMRI studies of cocaine-addicted individuals show impaired functional connectivity within and between frontostriatal circuits that is associated with compulsive drug use and trait impulsivity [61]. Although experiments designed to assess the genetic underpinnings of this phenomena have not been undertaken, there is evidence that $B \times D$ strains that display poor reversal learning have decreased D2 dopamine receptor expression in the brain [62] similar to the observation in human cocaine addicts [63].

Some rodent studies, although not all [64], indicate that the initial behavioral response induced by psychostimulants is predictive of subsequent higher levels of self-administration [65]. Cocaine-induced locomotor activity differed significantly across 45 inbred mouse strains, suggesting a likely genetic basis for these phenotypic differences [66]. A number of studies in rats have assessed various psychostimulant self-administration behaviors and have reported differences among (primarily inbred) strains [67-71]. Although the individual studies reveal interesting information, they are collectively problematic in that no one study has systematically examined a broad range of rat strains using consistent methodology and focusing on a specific psychostimulant. Thus, the extant literature suggests that there are differences in psychostimulant self-administration among rat strains but it is impossible to state with certainty the extent and magnitude of these disparities.

In a successful example of the use of animal models to investigate the genetic factors underlying cocaine addiction, a missense mutation in the Cyfip2 gene was shown to be the basis for differential acute cocaine locomotor response as well as behavioral sensitization in two substrains of the C57BL/6 model mouse [72]. C57BL/6 N mice maintained by the NIH for the International Knockout Mouse Consortium (IKMC) project show lower acute response and sensitization to cocaine at several doses than their C57BL/6 J counterparts, which are maintained at the Jackson Laboratory. An intercross quantitative trait loci (QTL) analysis between these two strains for cocaine response yielded a single QTL on chromosome 11. Further sequencing of this QTL revealed a single nonsynonymous SNP leading to a missense S968F mutation in the Cyfip2 gene, causing rapid degradation of the CYFIP2 proteins. Animals exhibiting the mutant allele have lower numbers of striatal medium spiny neuron spines and fewer mESPCs, which could account for their decreased cocaine sensitivity. Knockout of the Cyfip2 mutant allele partially restores cocaine sensitivity, thus strongly implicating Cyfip2 as being at least partially responsible for the differential cocaine behavioral phenotypes [72]. Thus, exploiting the vast amount of information regarding mouse genetics is a viable path to identifying novel targets for the development of therapeutics for cocaine addiction.

\section{EPIGENETICS}

Even though the identity of the specific genes underlying the heritability of cocaine addiction remains elusive, there is abundant evidence that repeated exposure to cocaine results in pronounced changes in gene expression in various nuclei, particularly in the limbic system. Candidate gene, gene array, and genome-wide approaches have delineated changes in gene expression in the nucleus accumbens, the hub of the limbic system that modulates numerous cocaine-mediated behaviors [73-76]. Changes in gene expression are regulated by complex interactions between transcription factors, chromatin, and epigenetic processes. Here, we will focus on epigenetics since the role of transcription factors in addiction have been reviewed in depth elsewhere [77, 78]. The identification of epigenetic mechanisms underlying cocaineinduced alterations in gene expression has accelerated in recent years and represents a promising new avenue for therapeutic development.

Although the definition of epigenetics is somewhat contentious (as reviewed in more detail in the next section focusing on crossgeneration effects), in the most general sense epigenetics is the study of molecular mechanisms that influence gene transcription without changing the DNA sequence. Examples include DNA methylation and post-translational modifications (PTMs) of histone $\mathrm{N}$-terminal tails, including acetylation and methylation. Epigenetic processes regulate the accessibility of the nearly two meters of DNA packaged into the nucleus of the vast majority of eukaryotic cells. In the nucleus, DNA is so tightly wrapped around octamers of histone proteins (two each of $\mathrm{H} 2 \mathrm{~A}, \mathrm{H} 2 \mathrm{~B}, \mathrm{H} 3$, and $\mathrm{H} 4$ ) that gene transcription cannot take place unless the DNA is first unwound. Each histone octamer is encircled with around 147 base pairs of DNA, a unit known as the nucleosome, which is somewhat analogous to thread (DNA) wrapped around a spool (histone). All nucleosomes together make up chromatin, which is further organized into chromosomes. The transition between open and closed chromatin regulates access by the transcriptional machinery to neighboring genes, thereby promoting or repressing gene transcription, respectively. Histone PTMs, which are added and removed by writer and eraser proteins, respectively, make up a "histone code", which is decrypted by reader molecules that recruit activating or repressing complexes and influence the compaction of chromatin.

During development, many genes in a given cell are silenced permanently in the process of cell fate determination. Generally, regions of the genome harboring more highly methylated areas of the genome are less transcriptionally active [79]. Thus, irrelevant genes in neurons, for example those associated with liver function, can be silenced during development through DNA methylation. Like histone PTMs, DNA methylation can and does change across the lifespan. Indeed, there are numerous examples of environment-mediated changes in DNA methylation and histone epigenetic modifications across the lifespan that alter phenotypes $[80,81]$. A growing literature focuses on epigenetic changes induced by drugs of abuse, including cocaine. Here, we review particularly salient examples of functionally relevant cocaineinduced histone PTMs or DNA methylation in the nucleus accumbens.

Histone PTMs

Although the list of histone PTMs continues to expand, neuroscience research has focused primarily on acetylation and methylation. Histone acetylation tends to result in open chromatin, which is permissive for gene transcription. The influence of histone methylation is more complex in that transcriptional enhancement or repression depends on the residue modified as well as the number of methyl marks added, which can vary from 1 to 3 . An early study examined genome-wide histone acetylation and methylation the day after seven days of experimenterdelivered cocaine in mice. Their results showed that cocaineinduced increases in the expression of genes including Arc, Cart, Cdk5 NFKB, and Period 1 were associated with increased $\mathrm{H} 3$ and/or $\mathrm{H} 4$ acetylation and either unchanged or decreased H3 
methylation [82]. Increased methylation at $\mathrm{H} 3$ following repeated cocaine injections was associated with decreased expression of Kv8.2, microtubule associated protein 2 and cGMP dependent protein kinase in the nucleus accumbens [82].

The effect of histone acetylation on cocaine-mediated behaviors has been assessed with histone deacetylase (HDAC) inhibitors, which attenuate the removal of acetyl groups from histone tail lysine residues thereby facilitating gene transcription. Most studies of this sort have focused on environmental conditioning associated with the subjective effects of cocaine in rodents as measured by the conditioned place preference (CPP) paradigm. Systemic administration of a general HDAC inhibitor facilitated the extinction of cocaine-mediated CPP and attenuated the subsequent reinstatement response [83]. HDACs are subdivided into subclasses. Class II HDACs include HDAC4 and HDAC5, which shuttle between the cytoplasm and nucleus in response to various cell signals. Over-expression of HDAC4 in the nucleus accumbens attenuated cocaine CPP [84]. Using the cocaine selfadministration paradigm, daily HDAC inhibitor treatment into the nucleus accumbens increased the motivation of rats to consume cocaine, an effect that was reversed by virally mediated overexpression of HDAC4 in the accumbens shell [85]. Cocainemediated CPP was enhanced in HDAC5 knockout mice, an effect that was reversed by increasing HDAC5 expression in the nucleus accumbens [86]. Repeated cocaine dephosphorylates HDAC5 resulting in its accumulation in the nucleus [87]. Accumbens expression of a mutant form of HDAC5 that cannot be phosphorylated at S279 attenuated the development of cocaine CPP [87]. There also is evidence that the sirtuins, which are class III HDACs, are involved in cocaine-mediated behavioral plasticity. Thus, repeated cocaine exposure increased H3 acetylation associated with Sirt1 and Sirt2 as well as Sirt1 and Sirt2 catalytic activity in the nucleus accumbens [82]. Administration of a sirtuin inhibitor directly into the nucleus accumbens attenuated both cocaine CPP and self-administration [82]. Collectively, these results indicate that cocaine-induced acetylation of histones increases the expression of various genes in the nucleus accumbens [88], which combine to promote cocaine conditioned reward as well as increase the reinforcing efficacy of cocaine.

In contrast to acetylation, histone methylation can either repress or activate gene transcription depending upon which histone residue is methylated and the number of methyl groups added. Early work on repressive marks modified by repeated cocaine focused on trimethylation of lysine 9 on histone H3 (H3K9me3). Repeated experimenter-delivered cocaine injections persistently reduced H3K9me3 abundance in the nucleus accumbens, which resulted in the unsilencing of LINE-1 retrotransposable elements, among other effects [89]. These modifications may reflect global changes in genomic stabilization in the nucleus accumbens following repeated cocaine [89]. A selectively bred rat line that displays persistent cocaine seeking was shown to have increased H3K9me3 association to D2 dopamine receptor (D2DR) promoter and decreased D2DR expression in the nucleus accumbens, with both normalizing following cocaine self-administration [90]. Repeated cocaine also decreased levels of the repressive mark, $\mathrm{H} 3 \mathrm{~K} 9 \mathrm{me2}$, in the nucleus accumbens, which was due to the repression of the lysine dimethyltransferase, G9a [91]. Viralmediated reduction in accumbal G9a increased cocaine-mediated CPP and enhanced the expression of a number of genes including several associated with cocaine-mediated dendritic changes in the nucleus accumbens [91]. Consistent with these results, overexpression of G9a specifically in D1DR-expressing, but not D2DRcontaining, accumbens neurons reduced cocaine CPP [92]. Taken together, these results indicate that changes in both activating and repressing histone methylation in the nucleus accumbens contribute to cocaine-induced neuronal and behavioral plasticity.

A recent genome-wide examination of the effects of repeated cocaine exposure focused on several repressive (H3K9me2,
H3K9me3, and H3K27me3) and activating (H3K4me1, H3K4me3, and H3K36me3) marks in the mouse nucleus accumbens. Their results indicated that cocaine produced substantial modifications in each of these marks at numerous genes and non-genic loci [74]. Somewhat surprisingly, repeated cocaine produced dramatic increases in alternative splicing in the accumbens. Indeed, repeated cocaine only regulated total transcript levels of around 100 genes, whereas over 1000 genes displayed altered splicing [74]. Further analysis of the neuron-specific splicing factor A2BP1 revealed that repeated cocaine resulted in translocation of $A 2 B P 1$ to the nucleus where it associated with $\mathrm{H} 3 \mathrm{~K} 4 \mathrm{me} 3$ and activated several hundred genes (including differential expression and alternative splicing). A functional role of $\mathrm{A} 2 \mathrm{BP} 1$ was confirmed in that conditional knockdown of $A 2 B P 1$ in the nucleus accumbens attenuated cocaine CPP [74]. Interestingly, H3K4me3 may also play an important role in mediating conditioned reward of other psychostimulants including methamphetamine. For example, viral-mediated knockdown of the H3K4me3 methyltransferase Mll1 in the nucleus accumbens attenuated CPP induced by methamphetamine [93].

$\mathrm{H} 3 \mathrm{~K} 4 \mathrm{me} 3$ is in close proximity to $\mathrm{H} 3 \mathrm{R} 2 \mathrm{me} 2 \mathrm{a}$, a repressive mark that counteracts the activating effect of $H 3$ K4me3. Protein-Rmethyltransferase-6 (PRMT6) is a nuclear enzyme that asymmetrically dimethylates $\mathrm{R} 2$ on $\mathrm{H} 3$. Recent evidence indicates that H3R2me2a and PRMT6 are decreased in the nucleus accumbens following repeated exposure to cocaine in mice, rats and humans [94]. Interestingly, these cocaine-induced decreases in accumbens H3R2me2a and PRMT6 occurred selectively in D2DR-containing accumbens output neurons, activation of which suppresses cocaine-mediated behavioral effects. Indeed, over-expression of PRMT6 in D2DR-containing accumbens neurons increased cocaine CPP [94]. The decrease in accumbens H3R2me2a was associated with increased $\mathrm{H} 3 \mathrm{~K} 4 \mathrm{me} 3$, which promoted the transcription of a small set of genes including Srcin1, a Src repressor that dampens the behavioral effects of cocaine [94].

Given the potentially broad effects of histone PTMs on gene expression, a challenge to the field is to develop methodologies to modulate histone PTMs as selectively as possible. To this end, engineered transcription factors were used to selectively modify chromatin at specific genes. Zinc-finger proteins (ZFPs) or transcription activator-like effectors (TALEs) were designed to recognize and bind to a narrowly defined locus in the genome and deliver specific histone modifications [95]. A recent study investigating the mechanism linking chromatin dynamics to reward pathology applied ZFP-p65 or ZFP-G9a, targeting histone H3 lysine 9/14 acetylation (H3K9/14ac), a transcriptionally active mark, or H3K9me2, which is associated with transcriptional repression, respectively, to the Fosb gene [95], the transcriptional regulation of which is strongly implicated in the actions of drugs of abuse $[91,96]$. These ZFPs were sufficient to modify histones at the targeted region of the Fosb promoter in nucleus accumbens and to control drug-evoked transcriptional and behavioral responses. Intriguingly, Fosb-ZFP-G9a was sufficient to block cocaine-induced Fosb activation via interference with CREB phosphorylation [95], providing direct evidence of the hierarchy between chromatin modifiers and transcription factors in gene regulation. More recent studies applied cell-type specific epigenetic editing using Fosb-ZFPs expressed in specific neuronal cell types using Cre-dependent HSV expression in mice transgenic for Cre recombinase in one of two types of accumbens principal neurons [97].

Fosb is just one of thousands of genes under epigenetic control in the context of drug exposure. There is growing evidence that cyclin-dependent kinase 5 (Cdk5) expression in accumbens influences reward-related behaviors [98]. A recent study found that HSV-mediated expression of ZFP-p65 and ZFP-G9a targeting the $C d k 5$ locus in NAc were sufficient to bidirectionally regulate Cdk5 gene expression via enrichment of their respective histone modifications at the Cdk5 promoter [99]. Further, Cdk5-targeted 
H3K9/14ac increased cocaine-induced locomotor behavior while Cdk5-targeted H3K9me2 attenuated cocaine reward. These data are especially compelling given that conventional Cdk5 overexpression or knockdown caused opposite behavioral phenotypes [98, 100, 101], demonstrating the importance of targeted epigenetic remodeling tools to invoke subtler, but physiologically-relevant, changes in gene regulation.

\section{DNA methylation}

Gene transcription also is profoundly influenced by cytosine modifications including methylation, which occurs mainly at $5^{\prime}$ cytosine-phosphate-guanine-3' (CpG) sites. Regions of DNA with a high concentration of CpG sites are known as CpG islands, which tend to be concentrated at promoters located near transcription start sites. Methylation of multiple CpGs in an island, via enzymes such as DNA methyltransferases (DNMTs), can result in the stable silencing of gene transcription. In contrast, cytosine methylation within the gene body can promote gene expression [102] Interactions with other proteins is necessary to produce DNA conformational changes. For example, methyl CpG binding protein 2 (MeCP2) binds to methylated DNA and recruits additional proteins to form a complex that can result in chromatin compaction, HDAC recruitment and transcription factor repulsion, all of which result in gene silencing. It also has been shown that in certain circumstances MeCP2 recruits the transcription factor CREB and promotes gene expression [103].

In animal models, cocaine exposure has been shown to induce global hypomethylation in the nucleus accumbens [104]. Somewhat surprisingly, rodents exposed to cocaine repeatedly also displayed persistently increased expression of methylationinducing Dnmt3a [105] and Dnmt3b [104]. Moreover, the increases in accumbens Dnmt3a following repeated cocaine were selective to D1DR-expressing neurons [106]. These changes in DNMTs were shown to be functional in that systemic administration of a methyl donor attenuated the development of cocaine-induced behavioral sensitization and cocaine priming-induced reinstatement of cocaine seeking [104]. Consistent with these results, viralmediated modulation of accumbens Dnmt3a resulted in opposing effects on cocaine CPP in that upregulation of accumbens Dnmt3a suppressed cocaine CPP, while down-regulation of accumbens Dnmt3a produced the opposite effect [105]. DNMT3a overexpression also reversed cocaine-induced increases in spine density in the accumbens [105].

The reinstatement of cue-induced cocaine seeking behavior, an animal model of craving, progressively increases, or "incubates", over the first several weeks following the cessation of cocaine selfadministration [107]. This is particularly interesting given that 1 day following cocaine self-administration Dnmt3a was decreased but Dnmt3a expression increased after 28 days of forced cocaine abstinence [105]. Consistent with this observation, the extent of DNA methylation in the nucleus accumbens was enhanced following 30 days of cocaine abstinence relative to the first day. These cocaine-induced increases in accumbens DNA methylation were at least partly negatively correlated with gene expression [108]. Intra-accumbens administration of a DNMT inhibitor attenuated the incubation of cocaine reinstatement, whereas a methyl donor enhanced cocaine cue-mediated reinstatement of drug seeking [108]. Administration of the DNMT inhibitor prior to the reinstatement session influenced a number of genes including demethylation of the estrogen receptor 1 (Esr1) promoter and activation of mRNA expression. A subsequent experiment revealed that an ESR1 agonist attenuated the incubation of cocaine reinstatement [108]. This work demonstrates how examination of patterns of DNA methylation following cocaine selfadministration can lead to the identification of novel potential therapeutic targets for cocaine addiction.

The transcriptional silencing effect of MeCP2 is mediated, in part, by its phosphorylation at Ser421, which is enhanced by exposure to amphetamine in a D2DR-dependent manner [109]. MeCP2 also appears to play a role in the conditioned rewarding effect of amphetamine in that viral-mediated knockdown of MeCP2 in the nucleus accumbens enhanced amphetamineinduced CPP, whereas over-expression of accumbens MeCP2 produced the opposite effect [109]. Cocaine self-administration increases MeCP2 expression in the dorsal striatum and viralmediated knockdown of $\mathrm{MeCP} 2$ in this brain region reduces cocaine self-administration [110]. Decreased dorsal striatal MeCP2 also potentiates the ability of cocaine to increase expression of the short non-coding RNA, miR-212 [110]. Viral-mediated increases in striatal miR-212 decreases the expression of BDNF, a neurotrophin that promotes enhanced cocaine intake [110]. It is important to note that microRNA-induced RNA silencing is a post-translational process that regulates gene expression and is, therefore, epigenetic [111]. While we do not include it in the scope of this review, an emerging literature focuses on the role of microRNAs in cocaine-induced neuronal and behavioral plasticity [112, 113].

Oxidation of 5-methylcytosine to products including 5hydroxymethylcytosine $(5 \mathrm{hmC})$ has been identified as an intermediate step to DNA demethylation, but recent evidence suggests $5 \mathrm{hmC}$ itself may function as an epigenetic mark to regulate gene expression. Repeated administration of cocaine increased $5 \mathrm{hmC}$ at gene body and intergenic regions associated with enhancer elements and alternative splicing sites [114]. Enrichment of 5hmC was associated with upregulation of genes involved in synaptic plasticity and implicated in addiction including Adcy1 and Nrtk2, a receptor for BDNF. Moreover, increased $5 \mathrm{hmC}$ concomitant with higher Adcy 1 and Nrtk2 gene expression persisted for one month following cocaine administration [114]. Interestingly, repeated cocaine delivery also downregulated expression of ten-eleven translocation 1 (Tet1), an enzyme known to catalyze the conversion of 5-methylcytosine to $5 \mathrm{hmC}$ [114]. Virally-mediated knockdown of Tet1 increased cocaine CPP and, counterintuitively, mirrored the effect of cocaine to enrich $5 \mathrm{hmC}$ in the same subset of genes [114]. This study highlights the importance of locus in determining the impact of epigenetic marks like methylation or hydroxymethylation as well as the effect of factors known to regulate their expression. Elucidating the role of novel epigenetic marks like $5 \mathrm{hmC}$ in the cellular and behavioral response to cocaine may be critical to fully understanding the epigenetic landscape of addiction.

\section{CROSS-GENERATIONAL EPIGENETICS}

One of the more interesting aspects of epigenetic regulation is the influence of parental life experiences on subsequent generations through stable epigenetic alterations in the germline. Unfortunately, the terminology in the general area of heritable epigenetics is not always standardized, often confusing and sometimes controversial. The very definition of the term epigenetics has been a source of debate, with each faction of related fields favoring one version over the other. The word was coined by Waddington [115] and literally means "above" or in "addition to" genetics. The standard definition of an epigenetic trait is a stably heritable phenotype resulting from changes in a chromosome without alterations in the DNA sequence [116] that are transmitted either to progeny through germline modifications or to daughter cells directly. In contrast, we have used the term epigenetics to describe all functional changes in DNA methylation and histone PTMs in neurons, the vast majority of which are postmitotic. Semantics aside, this section focuses on influences of exposure to cocaine on the behavior and physiology of descendants, with an emphasis on studies with an epigenetic mechanistic component.

In this context, another important distinction to make is the one between intergenerational and transgenerational effects of drug exposure. When the effects of environmental perturbations such 
as drug exposure are transmitted across generations and direct effects on fetuses or gametes cannot be ruled out, this is known as intergenerational heritability. Fetal alcohol syndrome is an example of intergenerational inheritance. A pregnant woman who drinks alcohol heavily puts her baby at risk of CNS damage among other signs and symptoms. Thus, maternal behavior can influence the phenotype of the offspring, which may or may not result from changes in the baby's DNA sequence or epigenetic marks. If the fetus is female, three generations are nested one inside of the other: the mother, the fetus and the primary oocytes that will ultimately produce the grandchildren. Paternal environmental insults also can produce intergenerational effects by influencing the sperm epigenome, which can reorient early developmental programming and impact progeny. Therefore, any changes in biology or behavior in the children (maternal and paternal lineage) or grandchildren (maternal lineage) could completely or partly result from direct exposure to the environmental insult making it difficult to tease apart the mechanisms underlying physiological changes in descendants.

In contrast, if transmission of the phenotype remains stable across multiple generations in the absence of fetus or oocyte exposure to the environmental perturbation, that is an example of transgenerational inheritance. Several instances of transgenerational heritability in humans have been reported. For example, around the turn of the twentieth century, the remote community of Överkalix, Sweden routinely experienced periods of food abundance and famine. Retrospective studies indicated that if the paternal grandfather experienced a period of food excess during the slow growth phase of adolescence, his grandsons had increased risk of diabetes-related mortality [117, 118]. The mechanism underlying this transgenerational phenomenon may be conserved germline epigenetic marks. This is a controversial concept since, traditionally, it was thought that all epigenetic marks were erased soon after fertilization. Moreover, sperm histones are replaced by protamines, which allows for higher chromatin compaction. Following fertilization, paternal protamines are replaced by histones of maternal origin [119]. Despite these steps to erase any current epigenetic information early on in development, it is now clear that some parental DNA methylation is conserved [120] and a limited number of paternal histones and their epigenetic marks are retained and influence development following fertilization [121]. Findings like these provide mechanistic bases for transgenerational epigenetic inheritance. What follows are several recent examples of heritable effects of exposure to cocaine. This section will focus on paternal manipulations, which circumvent some of the potentially confounding factors associated with studies of maternal cocaine exposure including changes in maternal behaviors. In rodent models, the sole contribution of sires to their progeny comes from the genetic and epigenetic material in their sperm. Hence studies of paternal cocaine exposure provide an opportunity to systematically delineate the possible modes of transmission from fathers to their descendants. This is by no means a comprehensive survey of this literature. Recent reviews provide a broader examination of the cross-generational influences of exposure to drugs of abuse [122-124].

In order to assess the effects of paternal cocaine exposure on offspring behavior, investigators have used different rodent models of addiction. Generally, male rodents were either allowed to self-administer cocaine or received non-contingent injections of cocaine for over two months, which covers the duration of spermatogenesis in mice and rats. During the latter stages of spermatogenesis, chromatin becomes highly compacted obviating modifications in epigenetic marks. Thus, there is a relatively short window of sensitivity when cocaine can plausibly interact with the epigenetic and transcriptional machineries in the germline to reprogram heritable epigenetic marks that can later influence neurodevelopment. Following the cocaine regimen, sires are mated with drug naïve females and the resulting first generation (F1) progeny were behaviorally assessed as adults. As the number of paternal cocaine exposure studies has grown, so too has the variability in the observed phenotypes on the next generation of animals. The unequivocal conclusions that can be reached from this research is that paternal cocaine exposure affects several behavioral modalities including propensity to consume drugs of abuse, reward processing, measures of mood and anxiety as well as cognitive processes [125-131].

Most publications have reported that paternal cocaine exposure has a protective effect on addiction-like behavior using either drug self-administration [126, 131] or conditioned place preference [132]. In two of these examples, the effects were specific to male offspring and cocaine-reward $[126,131]$. In sharp contrast, a multigenerational mouse model suggested that paternal cocaine affected both non-drug (sucrose) and cocaine-rewards in both male and female offspring [132]. These discrepancies highlight the need to assess both male and female progeny in these studies and underscore the complexity of how information can be carried across generations. One possibility is that the species used in the studies (mice vs. rat) can lead to divergent results, which is not surprising and consistent with a large body of research on this subject. The mechanisms underlying the sex specificity of many of the transgenerational effects of cocaine remain unclear and represent a major challenge for the field.

The jury is still out regarding changes in anxiety-like behavior, with reports noting an increase in anxiety-like behavior in the progeny of cocaine-exposed sires [127, 132] versus two other articles observing no change in baseline anxiety $[130,131]$. Given the fact that anxiety-like behavior is notoriously difficult to assess in rodents and the added variability in methodologies to generate the F1 generation, these discrepancies are perhaps not surprising. Similarly, about half of the publications reports deficits in cognitive capacities in progeny of cocaine-exposed sires [128, 129], while others observed no impact of paternal cocaine on memory in male or female offspring [130, 132].

Only a few articles have explored the neuroepigenetic mechanisms underlying the behavioral phenotypes derived from paternal cocaine exposure. The consensus is that BDNF mRNA and protein expression in the PFC of drug naïve, adult cocaine-sired rats are increased $[126,131]$ and that these changes are functionally relevant for reducing the reinforcing efficacy of cocaine in the male F1 cocaine-sired progeny [126]. Overexpression of BDNF was likely driven by increased acetylation of histone $\mathrm{H} 3$ in the PFC. Intriguingly, the association of acetylated histone $\mathrm{H} 3$ with Bdnf promoters was also increased in the sperm of sires that self-administered cocaine [126]. These findings indicated that paternal cocaine self-administration reprograms the germline resulting in enhanced BDNF expression in the $\mathrm{MPFC}$, which blunted the reinforcing efficacy of cocaine only in the male progeny. Another potential mode of transmission between sires and progeny is through methylation of DNA in sperm [131]. Some of the differences in DNA methylation elicited by paternal cocaine taking were maintained from the sires to the F1 generation, particularly near the transcription start sites of genes. These stable alterations to the germline epigenome could explain the transgenerational reduction in cocaine self-administration reported in both F1 and F2 male offspring [131].

The mode of drug delivery in sires (non contingent vs. selfadministration) may have a profound influence on the behavioral endpoints in the progeny. In fact, a recent study suggests that the motivational state of the sires for earning infusions of cocaine is a critical component for conferring a cocaine-resistance phenotype in the F1 generation and for reprogramming of the germline methylome by cocaine [131]. These kinds of studies begin to indirectly address the elusive question of how exactly cocaine reprograms the germline. There are cocaine binding sites in the testes, but it remains unclear whether reprogramming occurs as a 
consequence of direct interactions in the testes and/or through a combination of direct and indirect mechanisms that also involve cocaine's actions on the brain and/or endocrine systems. To date, no study has directly tackled this fascinating question. It is notable that the number of studies examining the impact of paternal cocaine exposure beyond the first generation offspring is extremely sparse [131].

Although the study of potential cross-generational effects of addictive drugs remains an emerging field, several intriguing effects have been delineated. It is particularly interesting that most of the influences of ancestral exposure to drugs of abuse are sex specific. As reviewed above, there is evidence that drugs of abuse can modify epigenetic marks in the germline. Sex-specific influences on progeny could result from changes in mitochondrial genes or genes found on the $Y$ chromosome. Genomic imprinting also is a plausible mechanism that thus far remains unexplored. The impact of sex hormones during development also may be suppressed or enhanced due to complex epigenetic effects leading to changes in behavior. There are well-characterized effects of female sex hormones on drug self-administration behavior [133]. Testosterone also has profound influences during development leading to a number of sexually dimorphic characteristics. For example, the bed nucleus of the stria terminalis, which plays an important role in addiction-related behaviors, is larger in males than females [134]. A major challenge going forward is to characterize drug-induced epigenetic changes in the germline that might plausibly influence physiology and behavior across generations. This is a significant hurdle for the entire field of transgenerational epigenetics, which will likely require the development of new methods to accurately trace the influence of a specific germline modification through embryogenesis and development.

\section{CONCLUSIONS}

According to PubMed, over 39,500 scientific papers focusing on cocaine have been published to date. Although we have reviewed only a small fraction of these articles here, the question remains: how can we know so much about the physiological effects of cocaine and still have no therapeutics for cocaine addiction? Fortunately, the situation is not completely bleak. There are some promising developments that could lead to therapeutics based on limiting the access of cocaine to the brain via a cocaine vaccine [135-137] or cocaine hydrolase [138, 139]. Initial studies also suggest that transcranial magnetic stimulation may produce prolonged reduction of cocaine intake in human addicts [140, 141]. Preclinical [142-146] as well as clinical case studies $[147,148]$ suggest that deep brain stimulation of the nucleus accumbens may be effective in the treatment of refractory cocaine dependence. We must acknowledge, however, that these advances are based on immunology, pharmacology and systems neuroscience rather than genetics or epigenetics.

The single genome wide analysis of genes associated with cocaine dependence failed to generate promising novel targets for cocaine therapeutic development [55]. This could be due to the fact that the heritability of cocaine addiction is highly polygenic and/or because the study was under-powered. It is now clear that GWASs focusing on psychiatric disorders require subject pools numbering in the tens of thousands. Human studies assessing specific genes in addiction have produced numerous positive effects, but the targets are derived almost exclusively from the animal literature. Given the staggering cost of human GWASs, animal genetic experiments are a more cost-effective and potentially equally valid alternative [72]. Cross-generational animal studies are a potential source of targets for cocaine addiction drug development. Multiple studies have shown that cocaine reinforcement is blunted in the male offspring of cocaine-exposed sires (Vassoler et al. 2013; [131, 132]). A comprehensive survey of the changes in gene expression and epigenetic marks in these cocaine-resistant rats has yet to be assessed and is critically important.

Therapeutics targeting epigenetic mechanisms are becoming more common, particularly in the treatment of various cancers. Valproate is an anticonvulsant that also used to treat bipolar disorder and migraine. The specific mechanism of action responsible for its therapeutic effects is unclear but valproate acts as an HDAC inhibitor, among other effects [149]. As reviewed above, animal studies indicate that HDAC inhibitors attenuate cocaine-induced conditioned place preference $[84,86,87]$ as well as cocaine self-administration [85]. Valproate is the subject of ongoing cocaine addiction clinical trials although published work has been mixed in terms of reducing cocaine use $[150,151]$ or craving [152]. A limitation of drugs such as valproate is a lack of specificity generally including its epigenetic influences. The latest epigenetic editing tools such as ZFPs and TALEs, which target specific genomic locations of epigenetic marks, have effectively modulated cocaine-mediated behaviors in animal studies $[95,99]$ and are likely to produce fewer side-effects than non-specific compounds such as general HDAC inhibitors. Exploiting these new developments in epigenetics in a clinical setting is clearly a distant prospect, but these kinds of advances hold the promise for new therapeutic developments for cocaine addiction, which are desperately needed.

\section{FUNDING}

This work was supported by the following NIH grants: DA39308 (MEW), DA44250 (EAH) DA40972 (WHB), DA33641 and DA40837 (RCP)

\section{ADDITIONAL INFORMATION}

Conflict of interest: The authors declare that they have no conflict of interest.

\section{REFERENCES}

1. Ahrnsbrak R, Bose J, Hedden S, Lipari R, Park-Lee E. Key substance use and mental health indicators in the United States: Results from the 2016 National Survey on Drug Use and Health. Administration SAaMHS. 2017. http://www. samhsa.gov/.

2. Pierce RC, O'Brien CP, Kenny PJ, Vanderschuren LJ. Rational development of addiction pharmacotherapies: successes, failures, and prospects. Cold Spring Harb Perspect Med. 2012;2:a012880.

3. Kampman KM, Leiderman D, Holmes T, LoCastro J, Bloch DA, Reid MS, et al. Cocaine rapid efficacy screening trials (CREST): lessons learned. Addiction. 2005;100:102-10.

4. Nuijten M, Blanken $P$, van de Wetering B, Nuijen B, van den Brink W, Hendriks VM. Sustained-release dexamfetamine in the treatment of chronic cocainedependent patients on heroin-assisted treatment: a randomised, double-blind, placebo-controlled trial. Lancet. 2016;387:2226-34.

5. Shearer J, Wodak A, van Beek I, Mattick RP, Lewis J. Pilot randomized double blind placebo-controlled study of dexamphetamine for cocaine dependence. Addiction. 2003:98:1137-41.

6. Dursteler-MacFarland KM, Farronato NS, Strasser J, Boss J, Kuntze MF, Petitjean $\mathrm{SA}$, et al. A randomized, controlled, pilot trial of methylphenidate and cognitivebehavioral group therapy for cocaine dependence in heroin prescription. J Clin Psychopharmacol. 2013;33:104-8.

7. Grabowski J, Rhoades H, Schmitz J, Stotts A, Daruzska LA, Creson D, et al. Dextroamphetamine for cocaine-dependence treatment: a double-blind randomized clinical trial. J Clin Psychopharmacol. 2001;21:522-6.

8. Tsuang MT, Lyons MJ, Meyer JM, Doyle T, Eisen SA, Goldberg J, et al. Cooccurrence of abuse of different drugs in men: the role of drug-specific and shared vulnerabilities. Arch Gen Psychiatry. 1998;55:967-72.

9. Kendler KS, Jacobson KC, Prescott CA, Neale MC. Specificity of genetic and environmental risk factors for use and abuse/dependence of cannabis, cocaine, hallucinogens, sedatives, stimulants, and opiates in male twins. Am J Psychiatry. 2003;160:687-95.

10. Olivares EL, Kendler KS, Neale MC, Gillespie NA. The genetic and environmental association between parental monitoring and risk of cannabis, stimulants, and cocaine initiation in a sample of male twins: does parenting matter? Twin Res Hum Genet. 2016;19:297-305. 
11. Wurbel H. Ideal homes? Housing effects on rodent brain and behaviour. Trends Neurosci. 2001;24:207-11.

12. Hill SY, Powell BJ. Cocaine and morphine self-administration: effects of differential rearing. Pharmacol Biochem Behav. 1976;5:701-4.

13. Bowling SL, Bardo MT. Locomotor and rewarding effects of amphetamine in enriched, social, and isolate reared rats. Pharmacol Biochem Behav. 1994:48:459-64.

14. Green TA, Gehrke BJ, Bardo MT. Environmental enrichment decreases intravenous amphetamine self-administration in rats: dose-response functions for fixed- and progressive-ratio schedules. Psychopharmacology. 2002;162:373-8.

15. Bardo MT, Klebaur JE, Valone JM, Deaton C. Environmental enrichment decreases intravenous self-administration of amphetamine in female and male rats. Psychopharmacology. 2001;155:278-84.

16. Fowler SC, Johnson JS, Kallman MJ, Liou JR, Wilson MC, Hikal AH. In a drug discrimination procedure isolation-reared rats generalize to lower doses of cocaine and amphetamine than rats reared in an enriched environment. Psychopharmacology. 1993;110:115-8.

17. Solinas M, Thiriet N, El Rawas R, Lardeux V, Jaber M. Environmental enrichment during early stages of life reduces the behavioral, neurochemical, and molecular effects of cocaine. Neuropsychopharmacology. 2009;34:1102-11.

18. Chauvet C, Lardeux V, Goldberg SR, Jaber M, Solinas M. Environmental enrichment reduces cocaine seeking and reinstatement induced by cues and stress but not by cocaine. Neuropsychopharmacology. 2009;34:2767-78.

19. Moos RH. Theory-based active ingredients of effective treatments for substance use disorders. Drug Alcohol Depend. 2007;88:109-21.

20. Merikangas KR, Stolar M, Stevens DE, Goulet J, Preisig MA, Fenton B, et al. Familial transmission of substance use disorders. Arch Gen Psychiatry. 1998;55:973-9.

21. Bierut LJ, Dinwiddie SH, Begleiter H, Crowe RR, Hesselbrock V, Nurnberger JI Jr., et al. Familial transmission of substance dependence: alcohol, marijuana, cocaine, and habitual smoking: a report from the Collaborative Study on the Genetics of Alcoholism. Arch Gen Psychiatry. 1998;55:982-8.

22. Kendler KS, Ohlsson $H$, Maes $H H$, Sundquist $K$, Lichtenstein $P$, Sundquist J. A population-based Swedish twin and sibling study of cannabis, stimulant and sedative abuse in men. Drug Alcohol Depend. 2015;149:49-54.

23. Kendler KS, Myers J, Prescott CA. Specificity of genetic and environmental risk factors for symptoms of cannabis, cocaine, alcohol, caffeine, and nicotine dependence. Arch Gen Psychiatry. 2007;64:1313-20.

24. Kendler KS, Karkowski LM, Neale MC, Prescott CA. Illicit psychoactive substance use, heavy use, abuse, and dependence in a US population-based sample of male twins. Arch Gen Psychiatry. 2000;57:261-9.

25. Kendler KS, Prescott CA. Cocaine use, abuse and dependence in a populationbased sample of female twins. Br J Psychiatry. 1998;173:345-50.

26. van den Bree MB, Johnson EO, Neale MC, Pickens RW. Genetic and environmental influences on drug use and abuse/dependence in male and female twins. Drug Alcohol Depend. 1998;52:231-41.

27. Goldman D, Oroszi G, Ducci F. The genetics of addictions: uncovering the genes. Nat Rev Genet. 2005;6:521-32.

28. Merikangas KR, Avenevoli S. Implications of genetic epidemiology for the prevention of substance use disorders. Addict Behav. 2000;25:807-20.

29. Agrawal A, Verweij KJ, Gillespie NA, Heath AC, Lessov-Schlaggar CN, Martin NG, et al. The genetics of addiction-a translational perspective. Transl Psychiatry. 2012;2:e140.

30. Kalayasiri R, Sughondhabirom A, Gueorguieva R, Coric V, Lynch WJ, Lappalainen $J$, et al. Dopamine beta-hydroxylase gene (DbetaH) -1021C-- > T influences selfreported paranoia during cocaine self-administration. Biol Psychiatry. 2007;61:1310-3.

31. Luo X, Kranzler H, Lappalainen J, Rosenheck R, Charney D, Zuo L, et al. CALCYON gene variation, schizophrenia, and cocaine dependence. Am J Med Genet Part B Neuropsychiatr Genet. 2004;125B:25-30.

32. Ittiwut R, Listman JB, Ittiwut C, Cubells JF, Weiss RD, Brady K, et al. Association between polymorphisms in catechol-O-methyltransferase (COMT) and cocaineinduced paranoia in European-American and African-American populations. Am J Med Genet Part B Neuropsychiatr Genet. 2011;156B:651-60.

33. Lohoff FW, Weller AE, Bloch PJ, Nall AH, Ferraro TN, Kampman KM, et al. Association between the catechol-O-methyltransferase Val158Met polymorphism and cocaine dependence. Neuropsychopharmacology. 2008;33:3078-84.

34. Multani PK, Clarke TK, Narasimhan S, Ambrose-Lanci L, Kampman KM, Pettinati $\mathrm{HM}$, et al. Neuronal calcium sensor- 1 and cocaine addiction: a genetic association study in African-Americans and European Americans. Neurosci Lett. 2012;531:46-51.

35. Martínez-Rivera A, Hao J, Tropea TF, Giordano TP, Kosovsky M, Rice RC, Lee A, Huganir RL, Striessnig J, Addy NA, Han S, Rajadhyaksha AM. Enhancing Ca $\mathrm{Ca}_{1.3} \mathrm{~L}$ type $\mathrm{Ca}^{2+}$ channel activity promotes cocaine and mood-related behaviors via overlapping AMPA receptor mechanisms in the nucleus accumbens. Mol Psychiatry. 2017;22:1735-45.
36. Zuo L, Kranzler HR, Luo X, Yang BZ, Weiss R, Brady K, et al. Interaction between two independent CNR1 variants increases risk for cocaine dependence in European Americans: a replication study in family-based sample and populationbased sample. Neuropsychopharmacology. 2009;34:1504-13.

37. Clarke TK, Bloch PJ, Ambrose-Lanci LM, Ferraro TN, Berrettini WH, Kampman KM, et al. Further evidence for association of polymorphisms in the CNR1 gene with cocaine addiction: confirmation in an independent sample and meta-analysis. Addict Biol. 2013;18:702-8.

38. Crist RC, Ambrose-Lanci LM, Vaswani M, Clarke TK, Zeng A, Yuan C, et al. Case-control association analysis of polymorphisms in the delta-opioid receptor, OPRD1, with cocaine and opioid addicted populations. Drug Alcohol Depend. 2013;127:122-8.

39. Crist RC, Doyle GA, Kampman KM, Berrettini WH. A delta-opioid receptor genetic variant is associated with abstinence prior to and during cocaine dependence treatment. Drug Alcohol Depend. 2016;166:268-71.

40. Dahl JP, Cubells JF, Ray R, Weller AE, Lohoff FW, Ferraro TN, et al. Analysis of variations in the tryptophan hydroxylase-2 (TPH2) gene in cocaine dependence. Addict Biol. 2006;11:76-83.

41. Dahl JP, Kampman KM, Oslin DW, Weller AE, Lohoff FW, Ferraro TN, et al. Association of a polymorphism in the Homer 1 gene with cocaine dependence in an African American population. Psychiatr Genet. 2005;15:277-83.

42. Kuryatov A, Berrettini W, Lindstrom J. Acetylcholine receptor (AChR) alpha5 subunit variant associated with risk for nicotine dependence and lung cancer reduces (alpha4beta2)(2)alpha5 AChR function. Mol Pharmacol. 2011;79:119-25.

43. Berrettini W, Yuan X, Tozzi F, Song K, Francks C, Chilcoat H, et al. Alpha-5/alpha-3 nicotinic receptor subunit alleles increase risk for heavy smoking. Mol Psychiatry. 2008;13:368-73.

44. Saccone SF, Hinrichs AL, Saccone NL, Chase GA, Konvicka K, Madden PA, et al. Cholinergic nicotinic receptor genes implicated in a nicotine dependence association study targeting 348 candidate genes with 3713 SNPs. Hum Mol Genet. 2007;16:36-49.

45. Thorgeirsson TE, Geller F, Sulem P, Rafnar T, Wiste A, Magnusson KP, et al. A variant associated with nicotine dependence, lung cancer and peripheral arterial disease. Nature. 2008;452:638-42.

46. Bierut LJ, Stitzel JA, Wang JC, Hinrichs AL, Grucza RA, Xuei X, et al. Variants in nicotinic receptors and risk for nicotine dependence. Am J Psychiatry. 2008;165:1163-71.

47. Demers $\mathrm{CH}$, Bogdan $\mathrm{R}$, Agrawal A. The Genetics, Neurogenetics and Pharmacogenetics of Addiction. Curr Behav Neurosci Rep. 2014;1:33-44.

48. Grucza RA, Wang JC, Stitzel JA, Hinrichs AL, Saccone SF, Saccone NL, et al. A risk allele for nicotine dependence in CHRNA5 is a protective allele for cocaine dependence. Biol Psychiatry. 2008;64:922-9.

49. Sadler B, Haller G, Agrawal A, Culverhouse R, Bucholz K, Brooks A, et al. Variants near CHRNB3-CHRNA6 are associated with DSM-5 cocaine use disorder: evidence for pleiotropy. Sci Rep. 2014;4:4497.

50. Sherva R, Kranzler HR, Yu Y, Logue MW, Poling J, Arias AJ, et al. Variation in nicotinic acetylcholine receptor genes is associated with multiple substance dependence phenotypes. Neuropsychopharmacology. 2010;35:1921-31.

51. Hansen ST, Mark GP. The nicotinic acetylcholine receptor antagonist mecamylamine prevents escalation of cocaine self-administration in rats with extended daily access. Psychopharmacology. 2007;194:53-61.

52. Levin ED, Mead T, Rezvani AH, Rose JE, Gallivan C, Gross R. The nicotinic antagonist mecamylamine preferentially inhibits cocaine vs. food selfadministration in rats. Physiol Behav. 2000;71:565-70.

53. Fowler CD, Lu Q, Johnson PM, Marks MJ, Kenny PJ. Habenular alpha5 nicotinic receptor subunit signalling controls nicotine intake. Nature. 2011;471:597-601.

54. Jensen KP. A review of genome-wide association studies of stimulant and opioid use disorders. Mol Neuropsychiatry. 2016;2:37-45.

55. Gelernter J, Sherva R, Koesterer R, Almasy L, Zhao H, Kranzler HR, et al. Genomewide association study of cocaine dependence and related traits: FAM53B identified as a risk gene. Mol Psychiatry. 2014;19:717-23.

56. Thermes V, Candal E, Alunni A, Serin G, Bourrat F, Joly JS. Medaka simplet (FAM53B) belongs to a family of novel vertebrate genes controlling cell proliferation. Development. 2006;133:1881-90.

57. Aoki $M$, Segawa $H$, Naito $M$, Okamoto $H$. Identification of possible downstream genes required for the extension of peripheral axons in primary sensory neurons. Biochem Biophys Res Commun. 2014;445:357-62.

58. Dickson PE, Miller MM, Calton MA, Bubier JA, Cook MN, Goldowitz D, et al. Systems genetics of intravenous cocaine self-administration in the BXD recombinant inbred mouse panel. Psychopharmacology. 2016;233:701-14.

59. Hao K, Chudin E, McElwee J, Schadt EE. Accuracy of genome-wide imputation of untyped markers and impacts on statistical power for association studies. BMC Genet. 2009;10:27. 
60. Cervantes MC, Laughlin RE, Jentsch JD. Cocaine self-administration behavior in inbred mouse lines segregating different capacities for inhibitory control. Psychopharmacology. 2013;229:515-25.

61. Hu Y, Salmeron BJ, Gu H, Stein EA, Yang Y. Impaired functional connectivity within and between frontostriatal circuits and its association with compulsive drug use and trait impulsivity in cocaine addiction. JAMA Psychiatry. 2015;72:584-92.

62. Groman SM, Lee B, Seu E, James AS, Feiler K, Mandelkern MA, et al. Dysregulation of $\mathrm{D}(2)$-mediated dopamine transmission in monkeys after chronic escalating methamphetamine exposure. J Neurosci. 2012;32:5843-52.

63. Ashok AH, Mizuno Y, Volkow ND, Howes OD. Association of stimulant use with dopaminergic alterations in users of cocaine, amphetamine, or methamphetamine: a systematic review and meta-analysis. JAMA Psychiatry. 2017;74:511-9.

64. Mandt $\mathrm{BH}$, Schenk $\mathrm{S}$, Zahniser NR, Allen RM. Individual differences in cocaine-induced locomotor activity in male Sprague-Dawley rats and their acquisition of and motivation to self-administer cocaine. Psychopharmacology. 2008;201:195-202.

65. Piazza PV, Deminiere JM, Le Moal M, Simon H. Factors that predict individual vulnerability to amphetamine self-administration. Science. 1989;245:1511-3.

66. Wiltshire T, Ervin RB, Duan H, Bogue MA, Zamboni WC, Cook S, et al. Initial locomotor sensitivity to cocaine varies widely among inbred mouse strains. Genes Brain Behav. 2015;14:271-80.

67. Meyer AC, Rahman S, Charnigo RJ, Dwoskin LP, Crabbe JC, Bardo MT. Genetics of novelty seeking, amphetamine self-administration and reinstatement using inbred rats. Genes Brain Behav. 2010;9:790-8.

68. Ward AS, Li DH, Luedtke RR, Emmett-Oglesby MW. Variations in cocaine selfadministration by inbred rat strains under a progressive-ratio schedule. Psychopharmacology. 1996;127:204-12.

69. Freeman KB, Kearns DN, Kohut SJ, Riley AL. Strain differences in patterns of drug-intake during prolonged access to cocaine self-administration. Behav Neurosci. 2009;123:156-64.

70. Jastrzebska J, Frankowska M, Szumiec L, Sadakierska-Chudy A, Haduch A, Smaga I, et al. Cocaine self-administration in Wistar-Kyoto rats: a behavioral and biochemical analysis. Behav Brain Res. 2015;293:62-73.

71. Kosten TA, Zhang XY, Haile CN. Strain differences in maintenance of cocaine self-administration and their relationship to novelty activity responses. Behav Neurosci. 2007;121:380-8.

72. Kumar V, Kim K, Joseph C, Kourrich S, Yoo SH, Huang HC, et al. C57BL/6N mutation in cytoplasmic FMRP interacting protein 2 regulates cocaine response. Science. 2013;342:1508-12.

73. Vallender EJ, Goswami DB, Shinday NM, Westmoreland SV, Yao WD, Rowlett JK. Transcriptomic profiling of the ventral tegmental area and nucleus accumbens in rhesus macaques following long-term cocaine self-administration. Drug Alcohol Depend. 2017;175:9-23.

74. Feng J, Wilkinson M, Liu X, Purushothaman I, Ferguson D, Vialou V, et al. Chronic cocaine-regulated epigenomic changes in mouse nucleus accumbens. Genome Biol. 2014;15:R65.

75. Freeman WM, Nader MA, Nader SH, Robertson DJ, Gioia L, Mitchell SM, et al Chronic cocaine-mediated changes in non-human primate nucleus accumbens gene expression. J Neurochem. 2001;77:542-9.

76. McClung CA, Nestler EJ. Regulation of gene expression and cocaine reward by CREB and DeltaFosB. Nat Neurosci. 2003;6:1208-15.

77. Nestler EJ. Molecular mechanisms of drug addiction. Neuropharmacology. 2004;47:24-32.

78. Robison AJ, Nestler EJ. Transcriptional and epigenetic mechanisms of addiction. Nat Rev Neurosci. 2011;12:623-37.

79. Suzuki MM, Bird A. DNA methylation landscapes: provocative insights from epigenomics. Nat Rev Genet. 2008;9:465-76.

80. Poulsen P, Esteller M, Vaag A, Fraga MF. The epigenetic basis of twin discordance in age-related diseases. Pediatr Res. 2007;61:38R-42R.

81. Fraga MF, Ballestar E, Paz MF, Ropero S, Setien F, Ballestar ML, et al. Epigenetic differences arise during the lifetime of monozygotic twins. Proc Natl Acad Sci USA. 2005;102:10604-9.

82. Renthal W, Kumar A, Xiao G, Wilkinson M, Covington HE 3rd, Maze I, et al. Genome-wide analysis of chromatin regulation by cocaine reveals a role for sirtuins. Neuron. 2009;62:335-48.

83. Malvaez M, Sanchis-Segura C, Vo D, Lattal KM, Wood MA. Modulation of chromatin modification facilitates extinction of cocaine-induced conditioned place preference. Biol Psychiatry. 2010;67:36-43.

84. Kumar A, Choi KH, Renthal W, Tsankova NM, Theobald DE, Truong HT, et al. Chromatin remodeling is a key mechanism underlying cocaine-induced plasticity in striatum. Neuron. 2005;48:303-14.

85. Wang L, Lv Z, Hu Z, Sheng J, Hui B, Sun J, et al. Chronic cocaine-induced H3 acetylation and transcriptional activation of CaMKIlalpha in the nucleus accumbens is critical for motivation for drug reinforcement. Neuropsychopharmacology. 2010;35:913-28.

86. Renthal W, Maze I, Krishnan V, Covington HE 3rd, Xiao G, Kumar A, et al. Histone deacetylase 5 epigenetically controls behavioral adaptations to chronic emotional stimuli. Neuron. 2007;56:517-29.

87. Taniguchi M, Carreira MB, Smith LN, Zirlin BC, Neve RL, Cowan CW. Histone deacetylase 5 limits cocaine reward through cAMP-induced nuclear import. Neuron. 2012;73:108-20.

88. Walker DM, Cates HM, Heller EA, Nestler EJ. Regulation of chromatin states by drugs of abuse. Curr Opin Neurobiol. 2015;30:112-21.

89. Maze I, Feng J, Wilkinson MB, Sun H, Shen L, Nestler EJ. Cocaine dynamically regulates heterochromatin and repetitive element unsilencing in nucleus accumbens. Proc Natl Acad Sci USA. 2011;108:3035-40.

90. Flagel SB, Chaudhury S, Waselus M, Kelly R, Sewani S, Clinton SM, et al. Genetic background and epigenetic modifications in the core of the nucleus accumbens predict addiction-like behavior in a rat model. Proc Natl Acad Sci USA. 2016;113: E2861-2870.

91. Maze I, Covington HE 3rd, Dietz DM, LaPlant Q, Renthal W, Russo SJ, et al. Essential role of the histone methyltransferase G9a in cocaine-induced plasticity. Science. 2010;327:213-6.

92. Maze I, Chaudhury D, Dietz DM, Von Schimmelmann M, Kennedy PJ, Lobo MK, et al. G9a influences neuronal subtype specification in striatum. Nat Neurosci. 2014;17:533-9.

93. Aguilar-Valles A, Vaissiere T, Griggs EM, Mikaelsson MA, Takacs IF, Young EJ, et al. Methamphetamine-associated memory is regulated by a writer and an eraser of permissive histone methylation. Biol Psychiatry. 2014;76:57-65.

94. Damez-Werno DM, Sun H, Scobie KN, Shao N, Rabkin J, Dias C, et al. Histone arginine methylation in cocaine action in the nucleus accumbens. Proc Natl Acad Sci USA. 2016;113:9623-8.

95. Heller EA, Cates HM, Pena CJ, Sun H, Shao N, Feng J, et al. Locus-specific epigenetic remodeling controls addiction- and depression-related behaviors. Nat Neurosci. 2014;17:1720-7.

96. Renthal W, Nestler EJ. Epigenetic mechanisms in drug addiction. Trends Mol Med. 2008;14:341-50.

97. Hamilton PJ, Burek DJ, Lombroso SI, Neve RL, Robison AJ, Nestler EJ, et al. Celltype-specific epigenetic editing at the fosb gene controls susceptibility to social defeat stress. Neuropsychopharmacology. 2018;43:272-84.

98. Bibb JA, Chen J, Taylor JR, Svenningsson P, Nishi A, Snyder GL, et al. Effects of chronic exposure to cocaine are regulated by the neuronal protein $\mathrm{Cdk5}$. Nature. 2001;410:376-80

99. Heller EA, Hamilton PJ, Burek DD, Lombroso SI, Pena CJ, Neve RL, et al. Targeted epigenetic remodeling of the $\mathrm{Cdk} 5$ gene in nucleus accumbens regulates cocaine- and stress-evoked behavior. J Neurosci. 2016;36:4690-7.

100. Meyer DA, Richer E, Benkovic SA, Hayashi K, Kansy JW, Hale CF, et al. Striatal dysregulation of Cdk5 alters locomotor responses to cocaine, motor learning, and dendritic morphology. Proc Natl Acad Sci USA. 2008;105:18561-6.

101. Taylor JR, Lynch WJ, Sanchez H, Olausson P, Nestler EJ, Bibb JA. Inhibition of Cdk5 in the nucleus accumbens enhances the locomotor-activating and incentive-motivational effects of cocaine. Proc Natl Acad Sci USA. 2007;104:4147-52.

102. Vaillancourt K, Ernst C, Mash D, Turecki G. DNA methylation dynamics and cocaine in the brain: progress and prospects. Genes. 2017;8:E138.

103. Fasolino $M, Z$ Zhou $Z$. The crucial role of DNA methylation and MeCP2 in neuronal function. Genes. 2017;8:E141

104. Wright KN, Hollis F, Duclot F, Dossat AM, Strong CE, Francis TC, et al. Methyl supplementation attenuates cocaine-seeking behaviors and cocaine-induced $C$ Fos activation in a DNA methylation-dependent manner. J Neurosci. 2015;35:8948-58.

105. LaPlant Q, Vialou V, Covington HE 3rd, Dumitriu D, Feng J, Warren BL, et al. Dnmt3a regulates emotional behavior and spine plasticity in the nucleus accumbens. Nat Neurosci. 2010;13:1137-43.

106. Heiman M, Schaefer A, Gong S, Peterson JD, Day M, Ramsey KE, et al. A translational profiling approach for the molecular characterization of CNS cell types. Cell. 2008:135:738-48.

107. Grimm JW, Hope BT, Wise RA, Shaham Y. Neuroadaptation. Incubation of cocaine craving after withdrawal. Nature. 2001;412:141-2.

108. Massart R, Barnea R, Dikshtein Y, Suderman M, Meir O, Hallett M, et al. Role of DNA methylation in the nucleus accumbens in incubation of cocaine craving. $J$ Neurosci. 2015;35:8042-58.

109. Deng JV, Rodriguiz RM, Hutchinson AN, Kim IH, Wetsel WC, West AE. MeCP2 in the nucleus accumbens contributes to neural and behavioral responses to psychostimulants. Nat Neurosci. 2010;13:1128-36.

110. Im HI, Hollander JA, Bali P, Kenny PJ. MeCP2 controls BDNF expression and cocaine intake through homeostatic interactions with microRNA-212. Nat Neurosci. 2010;13:1120-7. 
111. Sato F, Tsuchiya S, Meltzer SJ, Shimizu K. MicroRNAs and epigenetics. FEBS J. 2011;278:1598-609.

112. Doura MB, Unterwald EM. MicroRNAs modulate interactions between stress and risk for cocaine addiction. Front Cell Neurosci. 2016;10:125.

113. Bastle RM, Oliver RJ, Gardiner AS, Pentkowski NS, Bolognani F, Allan AM, et al. In silico identification and in vivo validation of miR-495 as a novel regulator of motivation for cocaine that targets multiple addiction-related networks in the nucleus accumbens. Mol Psychiatry. 2018;23:434-43.

114. Feng J, Shao N, Szulwach KE, Vialou V, Huynh J, Zhong C, et al. Role of Tet1 and 5-hydroxymethylcytosine in cocaine action. Nat Neurosci. 2015;18:536-44.

115. Waddington $\mathrm{CH}$. Canalization of development and genetic assimilation of acquired characters. Nature. 1959;183:1654-5.

116. Berger SL, Kouzarides T, Shiekhattar R, Shilatifard A. An operational definition of epigenetics. Genes Dev. 2009;23:781-3.

117. Pembrey ME, Bygren LO, Kaati G, Edvinsson S, Northstone K, Sjostrom M, et al. Sex-specific, male-line transgenerational responses in humans. Eur J Hum Genet. 2006;14:159-66

118. Kaati G, Bygren LO, Edvinsson S. Cardiovascular and diabetes mortality determined by nutrition during parents' and grandparents' slow growth period. Eur J Hum Genet. 2002;10:682-8.

119. Puri D, Dhawan J, Mishra RK. The paternal hidden agenda: epigenetic inheritance through sperm chromatin. Epigenetics. 2010;5:386-91.

120. Hackett JA, Sengupta R, Zylicz JJ, Murakami K, Lee C, Down TA, et al. Germline DNA demethylation dynamics and imprint erasure through 5hydroxymethylcytosine. Science. 2013;339:448-52.

121. Hammoud SS, Nix DA, Zhang $H$, Purwar J, Carrell DT, Cairns BR. Distinctive chromatin in human sperm packages genes for embryo development. Nature. 2009;460:473-8.

122. Vassoler FM, Byrnes EM, Pierce RC. The impact of exposure to addictive drugs on future generations: physiological and behavioral effects. Neuropharmacology. 2014a;76:269-75.

123. Vassoler FM, Sadri-Vakili G. Mechanisms of transgenerational inheritance of addictive-like behaviors. Neuroscience. 2014b;264C:198-206.

124. Yohn NL, Bartolomei MS, Blendy JA. Multigenerational and transgenerational inheritance of drug exposure: the effects of alcohol, opiates, cocaine, marijuana, and nicotine. Prog Biophys Mol Biol. 2015;118:21-33.

125. Abel EL, Moore C, Waselewsky D, Zajac C, Russell LD. Effects of cocaine hydrochloride on reproductive function and sexual behavior of male rats and on the behavior of their offspring. J Androl. 1989;10:17-27.

126. Vassoler FM, White SL, Schmidt HD, Sadri-Vakili G, Pierce RC. Epigenetic inheritance of a cocaine-resistance phenotype. Nat Neurosci. 2013b;16:42-47.

127. White SL, Vassoler FM, Schmidt HD, Pierce RC, Wimmer ME. Enhanced anxiety in the male offspring of sires that self-administered cocaine. Addict. Biol. 2016;21:802-10.

128. Wimmer ME, Briand LA, Fant B, Guercio LA, Arreola AC, Schmidt HD, et al. Paternal cocaine taking elicits epigenetic remodeling and memory deficits in male progeny. Mol Psychiatry. 2017;22:1641-50.

129. He F, Lidow IA, Lidow MS. Consequences of paternal cocaine exposure in mice. Neurotoxicol Teratol. 2006;28:198-209.

130. Killinger CE, Robinson S, Stanwood GD. Subtle biobehavioral effects produced by paternal cocaine exposure. Synapse. 2012;66:902-8.

131. Le Q, Yan B, Yu X, Li Y, Song H, Zhu H, et al. Drug-seeking motivation level in male rats determines offspring susceptibility or resistance to cocaine-seeking behaviour. Nat Commun. 2017;8:15527.

132. Fischer DK, Rice RC, Martinez Rivera A, Donohoe M, Rajadhyaksha AM. Altered reward sensitivity in female offspring of cocaine-exposed fathers. Behav Brain Res. 2017;332:23-31.

133. Becker JB, Hu M. Sex differences in drug abuse. Front Neuroendocrinol. 2008;29:36-47.
134. Chung WC, Swaab DF, De Vries GJ. Apoptosis during sexual differentiation of the bed nucleus of the stria terminalis in the rat brain. J Neurobiol. 2000;43:234-43.

135. Wee S, Hicks MJ, De BP, Rosenberg JB, Moreno AY, Kaminsky SM, et al. Novel cocaine vaccine linked to a disrupted adenovirus gene transfer vector blocks cocaine psychostimulant and reinforcing effects. Neuropsychopharmacology. 2011.

136. Kantak KM, Collins SL, Lipman EG, Bond J, Giovanoni K, Fox BS. Evaluation of anti-cocaine antibodies and a cocaine vaccine in a rat self-administration model. Psychopharmacology. 2000;148:251-62.

137. Kinsey BM, Kosten TR, Orson FM. Anti-cocaine vaccine development. Expert Rev Vaccine. 2010;9:1109-14.

138. Zlebnik NE, Brimijoin S, Gao Y, Saykao AT, Parks RJ, Carroll ME. Long-term reduction of cocaine self-administration in rats treated with adenoviral vectordelivered cocaine hydrolase: evidence for enzymatic activity. Neuropsychopharmacology. 2014;39:1538-46.

139. Chen X, Xue L, Hou S, Jin Z, Zhang $T$, Zheng F, et al. Long-acting cocaine hydrolase for addiction therapy. Proc Natl Acad Sci USA. 2016;113:422-7.

140. Bolloni C, Panella R, Pedetti M, Frascella AG, Gambelunghe C, Piccoli $T$, et al. Bilateral transcranial magnetic stimulation of the prefrontal cortex reduces cocaine intake: a pilot study. Front Psychiatry. 2016;7:133.

141. Hanlon CA, Dowdle LT, Jones JL. Biomarkers for success: using neuroimaging to predict relapse and develop brain stimulation treatments for cocainedependent individuals. Int Rev Neurobiol. 2016;129:125-56.

142. Pierce RC, Vassoler FM. Deep brain stimulation for the treatment of addiction: basic and clinical studies and potential mechanisms of action. Psychopharmacology. 2013;229:487-91.

143. Vassoler FM, Schmidt HD, Gerard ME, Famous KR, Ciraulo DA, Kornetsky C, et al. Deep brain stimulation of the nucleus accumbens shell attenuates cocaine priming-induced reinstatement of drug seeking in rats. J Neurosci. 2008;28:8735-9.

144. Vassoler FM, White SL, Hopkins TJ, Guercio LA, Espallergues J, Berton O, et al. Deep brain stimulation of the nucleus accumbens shell attenuates cocaine reinstatement through local and antidromic activation. J Neurosci. 2013a;33:14446-54.

145. Creed M, Pascoli VJ, Luscher C. Addiction therapy. Refining deep brain stimulation to emulate optogenetic treatment of synaptic pathology. Science. 2015;347:659-64.

146. Guercio LA, Schmidt HD, Pierce RC. Deep brain stimulation of the nucleus accumbens shell attenuates cue-induced reinstatement of both cocaine and sucrose seeking in rats. Behav Brain Res. 2015;281:125-30.

147. Goncalves-Ferreira A, do Couto FS, Rainha Campos A, Lucas Neto LP, GoncalvesFerreira $D$, Teixeira J. Deep brain stimulation for refractory cocaine dependence. Biol Psychiatry. 2016;79:e87-89.

148. Luigjes J, van den Brink W, Feenstra M, van den Munckhof P, Schuurman PR, Schippers $R$, et al. Deep brain stimulation in addiction: a review of potential brain targets. Mol Psychiatry. 2012;17:572-83.

149. Ghodke-Puranik Y, Thorn CF, Lamba JK, Leeder JS, Song W, Birnbaum AK, et al. Valproic acid pathway: pharmacokinetics and pharmacodynamics. Pharm Genom. 2013;23:236-41.

150. Reid MS, Casadonte $P$, Baker $S$, Sanfilipo M, Braunstein D, Hitzemann R, et al. A placebo-controlled screening trial of olanzapine, valproate, and coenzyme Q10/L-carnitine for the treatment of cocaine dependence. Addiction. 2005;100:43-57.

151. Halikas JA, Center BA, Pearson VL, Carlson GA, Crea F. A pilot, open clinical study of depakote in the treatment of cocaine abuse. Hum Psychopharmacol. 2001;16:257-64.

152. Reid MS, Thakkar V. Valproate treatment and cocaine cue reactivity in cocaine dependent individuals. Drug Alcohol Depend. 2009;102:144-50. 